\title{
Effect of Lime Stabilisation on the Strength and Microstructure of Clay
}

\author{
${ }^{1}$ Asma Muhmed and ${ }^{2}$ DariuszWanatowski \\ ${ }^{1}$ AsmaMuhmedis with the University of Nottingham, United Kingdom, on leave from Omar Al- \\ MukhtarUniversity, Libya \\ ${ }^{2}$ DariuszWanatowski is with the University ofNottingham, China
}

\begin{abstract}
Lime stabilization is one of the techniques that can be used for improving the engineering properties, particularly the strength, of soft clays. This paper aims to investigate the effect of hydrated lime on the strength and microstructure of lime treated clays. In order to illustrate such effect, a series of laboratory tests were conducted. Atterberg limits, compaction tests, unconfined compressive strength tests and scanning electron microscope (SEM) were carried out on kaolin clay mixed with $5 \%$ hydrated lime. The results indicated that the addition of lime resulted in a reduction in the plasticity of kaolin and an improvement in compaction properties. The unconfined compressive strength (UCS) of stabilized clay experienced an increase with lime addition. Two variables influencing the amount of strength developed were studied. These variables included curing time and water content. Curing time contributed to an increase in the UCS, from $183 \mathrm{kPa}$ to $390 \mathrm{kPa}$, that is approximately twice of the strength of untreated kaolin. SEM analysis showed the presence of the cementious products in the kaolin clay resulted from lime-clay reaction.
\end{abstract}

Key words:Lime, Stabilisation, Soft clay, Pozzolanic reaction, Mineralogy

\section{Introduction}

Clay soils are normally associated with volumetric changes when subjected to changes in water content because of the seasonal water fluctuations. Furthermore, problems with clays, including low strength and high compressibility, can cause severe damage to civil engineering construction. Therefore, these soils must be treated before commencing the construction operation to achieve desired properties. Different methods are available to improve the engineering properties of problematic soils such as densification, chemical stabilisation, reinforcement and techniques of pore water pressure reduction. The chemical stabilisation of clays using lime is one of the commonest methods that can be used to upgrade the soils of poor properties to provide a workable platform to construction projects [1]. According to [2], the need for developing new materials for stabilisation started in the late 1940s.

The chemical reactions between clay particles and lime can be categorised into two forms of improvement, short term reaction (modification) and long term reaction (stabilisation). In the first reaction the process of ion exchanges makes the clay minerals flocculate and agglomerate leading to a reduction in plasticity, swell and moisture content. The second reaction (pozzolanic reaction) accomplishes over a period of time creating cementing products that cause long-term strength gain [3].

This paper aims to investigate the strength and the microstructure of lime treated clay using unconfined compressive strength test and scanning electron microscope (SEM) analysis. For this purpose, Eedes and Grim's method was used to determine the required amount of hydrated lime to be mixed with commercial kaolin. Kaolin-lime mixtures were prepared with 5\% lime and compacted at optimum moisture content (OMC), and at wet and dry of the OMC in order to investigate the influence of curing time required and water content needed for successful lime treatment.

\section{Experimental Program}

In order to investiggate the effect of hydrated lime on the physical and engineering properties, both untreated and treated kaolin were subjected to similar laboratory tests. These tests include Atterberg limits test, compaction test, unconfined compressive strength test (UCS) and scanning electron microscope (SEM). The effect of curing time and water content on the UCS and microstructure of lime treated clay was also studied. The first step for stabilisation with lime in the present study was to determine the minimum amount of lime required for long-term improvement of strength.

\section{Test Materials}

The soil tested in this study is commercial kaolin clay. It was mixed with 5\% lime (determined based on Initial Consumption of Lime). A fine ground hydrated lime (calcium hydroxide $-\mathrm{Ca}[\mathrm{OH}]_{2}$ ) was used. Table 1 summarises the basic properties of untreated kaolin. 
Table 1: Basic properties of untreated kaolin

\begin{tabular}{ll} 
Property & Value \\
\hline Specific Gravity & 2.61 \\
Liquid Limit, \% & 65.9 \\
Plastic Limit, \% & 33.3 \\
Plasticity Index,\% & 32.6 \\
Maximum Dry Density, $\mathrm{kg} / \mathrm{m}^{3}$ & 1422 \\
Optimum Moisture Content, \% & 29.9 \\
Unconfined Compressive Strength, $\mathrm{kN} / \mathrm{m}^{2}$ & 183 \\
$\mathrm{pH}$ & 5.43 \\
\hline
\end{tabular}

\section{Specimen Preparation}

The clay samples were firstly dried at $60^{\circ} \mathrm{C}$ before mixing. To prepare the lime-clay mixtures, the required amounts of dry kaolin were mixed with 5\% of hydrated lime by weight of kaolin in the dry state until an even distribution of lime in mixture was obtained. The dry lime-clay mixtures were then mixed with distilled water. These mixtures were used for Attreberg limit and compaction tests. The moisture contents chosen for the present study corresponded to the optimum moisture content (OMC), wet side of OMC (WMC) and dry side of the OMC (DMC) of the treated and untreated kaolin determined from the compaction tests. These moisture contents were used for preparing the specimens for the unconfined compressive strength test.

\section{Test Results}

Initial Consumption of Lime (ICL)

The $\mathrm{pH}$ test is the preferred method for identifying the lime content required to obtain a long-term pozzolanic reaction. In order to determine the minimum lime content required, the method developed by [4] was used. The plot of $\mathrm{pH}$ valuescorrected at $25^{\circ} \mathrm{C}$ versus lime content are presented in Fig. 1. It can be seen that, the initial lime content needed for the lime treatment of clay is $2 \%$. Therefore, this percentage of hydrated lime could be used. However, according to [5], for optimum improvement of the soil strength the optimum lime content for kaolin is in the range of $4 \%$ to $6 \%$. Therefore, in the current study, 5\% of hydrated lime by weight was chosen for thestabilization.

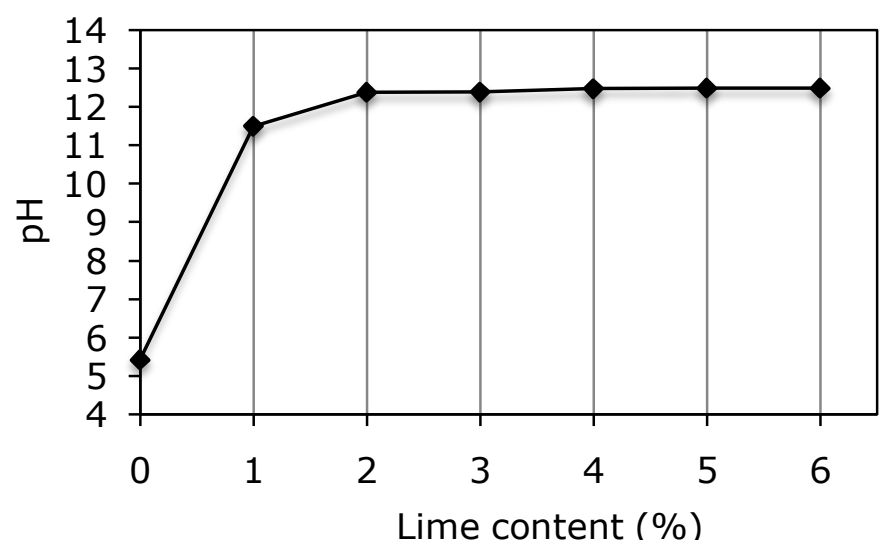

Fig. 1: Determination of the initial consumption of lime

\section{Atterberg Limit Test}

Attreberg limits were determined according to [6]. The liquid limit (LL), in the penetrometer method, of the soil is the moisture content at which an $80 \mathrm{~g}, 30^{\circ}$ cone sinks exactly $20 \mathrm{~mm}$ into a cup of remoulded soil in a 5 seconds period. At this moisture content, the soil will be very soft. The plastic limit (PL) is the water content in which soil starts to crack when rolled between the fingers on glass plate to form a thread of $3 \mathrm{~mm}$ diameter. At this point, the soil has a stiff consistency. The difference between LL and PL is plasticity index. 


\section{Proctor's Compaction Test}

The optimum moisture content (OMC) and the maximum dry density (MDD) of the clay were obtained using the Standard Proctor compaction test carried out according to [6]. The test was performed by the compaction of the clay into a mould that is filled at a fixed moisture content in three, approximately, equal layers of clay. The compaction is achieved by a standard number of blows ( 27 blows) from a hand rammer of $2.5 \mathrm{~kg}$ dropping from a height of $300 \mathrm{~mm}$.

\section{Unconfined Compression Strength (UCS) Test}

The UCS testing was performed according to [6]. For this test, samples of kaolin and lime treated kaolin were compacted at optimum moisture content (OMC) and at wet and dry side of OMC by hand in three layers in cylindrical mould of $38 \mathrm{~mm}$ in diameter and $76 \mathrm{~mm}$ in height. All specimens were taken out from the moulds and cured at $20^{\circ} \mathrm{C}$ for 7,14 and 28 days. After reaching the specified curing time, the cylindrical specimens were subjected to a gradually increased axial compression load until failure. All the specimens were tested at an axial strain rate of $1 \%$ per minute.

\section{Scanning Electron Microscope}

In order to observe the influence of lime addition on the microstructure of the studied clay, Scanning Electron Microscope (SEM) analysis was used to investigate the microstructural development of the tested kaolin. After UCS testing, the tested samples were dried for SEM. Small specimens of both untreated and treated clay samples were prepared and the fractured surfaces of the specimens were coated with gold before scanning.

\section{Discussion Of Test Results}

\section{Influence of Lime on Atterberg Limits}

Fig. 2 shows Atterberg limits for $0 \%$ and 5\% of lime. It can be observed from Fig. 2, there is a reduction in the Plasticity Index and an increase in both liquid and plastic limits with the addition of lime. The liquid limit increased by $20.6 \%$ when $5 \%$ of lime was added. The increase is more evident in the plastic limit which increased from $33.3 \%$ to $56.9 \%$.

According to [7] and [8], the reduction in the plasticity makes soils more friable and easily workable. Plasticity decreases because calcium ions from the lime reduce the volumetric changes. Furthermore, the aggregates, formed from the flocculation of the soil particles, behave more like silt rather than clay particles. Another study, conducted by [9], also offers evidence in support of the increase of the liquid limit. These investigations showed that the liquid limits of kaolinite rich soils increased when lime was added. However, liquid limit change is less important, for geotechnical engineers comparing with the plastic limit; this is because the maximum soil strength is attained when the soil is compacted at OMC that is close to the plastic limit as proved in this project.

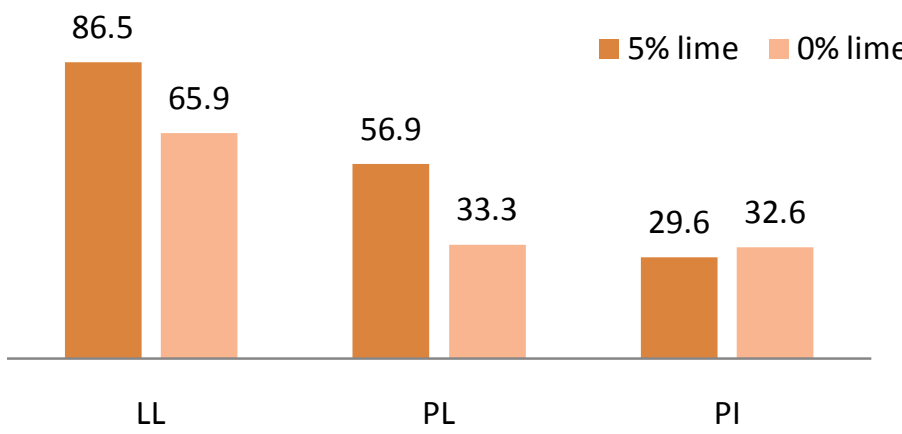

Fig. 2:Atterberg limits at $0 \%$ and $5 \%$ lime content

\section{Influence of Lime on Compaction Characteristics}

Fig. 3 illustrates the moisture-density relationship of kaolin with $0 \%$ and 5\% lime. As shown in the Fig. 3 , the addition of lime tends to increase the optimum moisture content (OMC) and reduce the maximum dry density (MDD). For the same compaction effort, the optimum moisture content of the untreated clay changed from $29.9 \%$ to $33.3 \%$ when $5 \%$ lime was added to the clay. The maximum density decreased from $1422 \mathrm{~kg} / \mathrm{m}^{3}$ to $1382 \mathrm{~kg} / \mathrm{m}^{3}$. This change is considered as an indication of the improvement of the compaction characteristics of the lime stabilised clay. This is consistent with the study conducted by [10]. The reduction in the dry density 
occurs because the agglomerated and flocculated particles of soil occupy larger spaces and the reason for increasing $\mathrm{OMC}$ is that, the lime requires more water for the pozzolanic reactions. [11] referred the decrease in density to the difference in the specific gravity of the clay and hydrated lime.

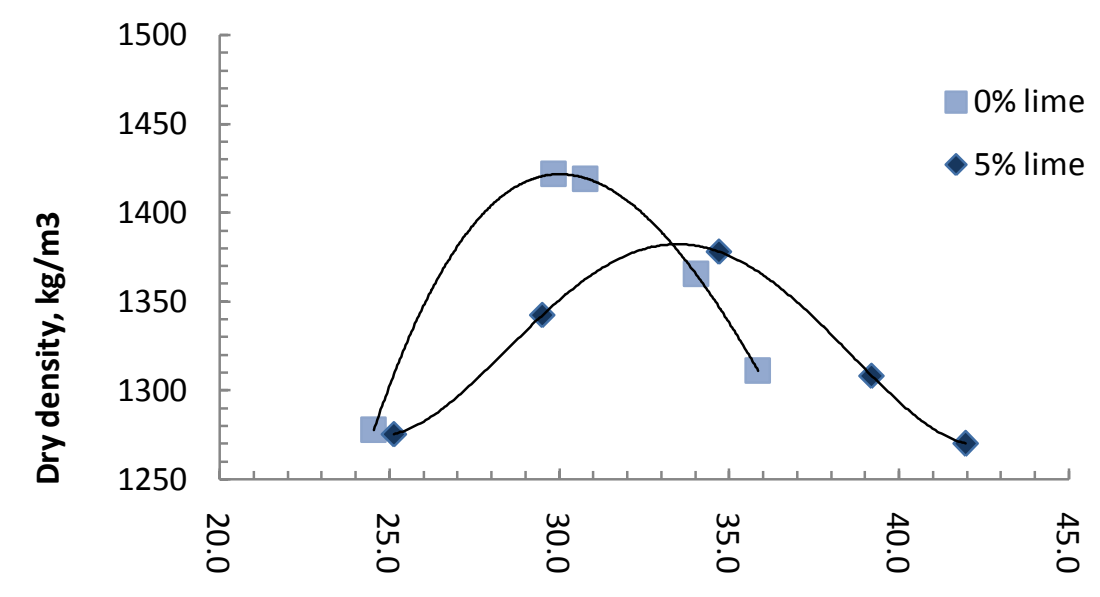

Moisture content, \%

Fig. 3:Influence of lime on compaction characteristics of clay

\section{Influence of Lime on Unconfined Compressive Strength (UCS)}

Fig.4 shows the stress-strain behaviour of untreated kaolin and kaolin treated with 5\% lime and compacted at OMC. As can be seen, the untreated clay failed at the UCS of $183 \mathrm{kPa}$, whereas treated clay at different curing time failed at higher values of the UCS.

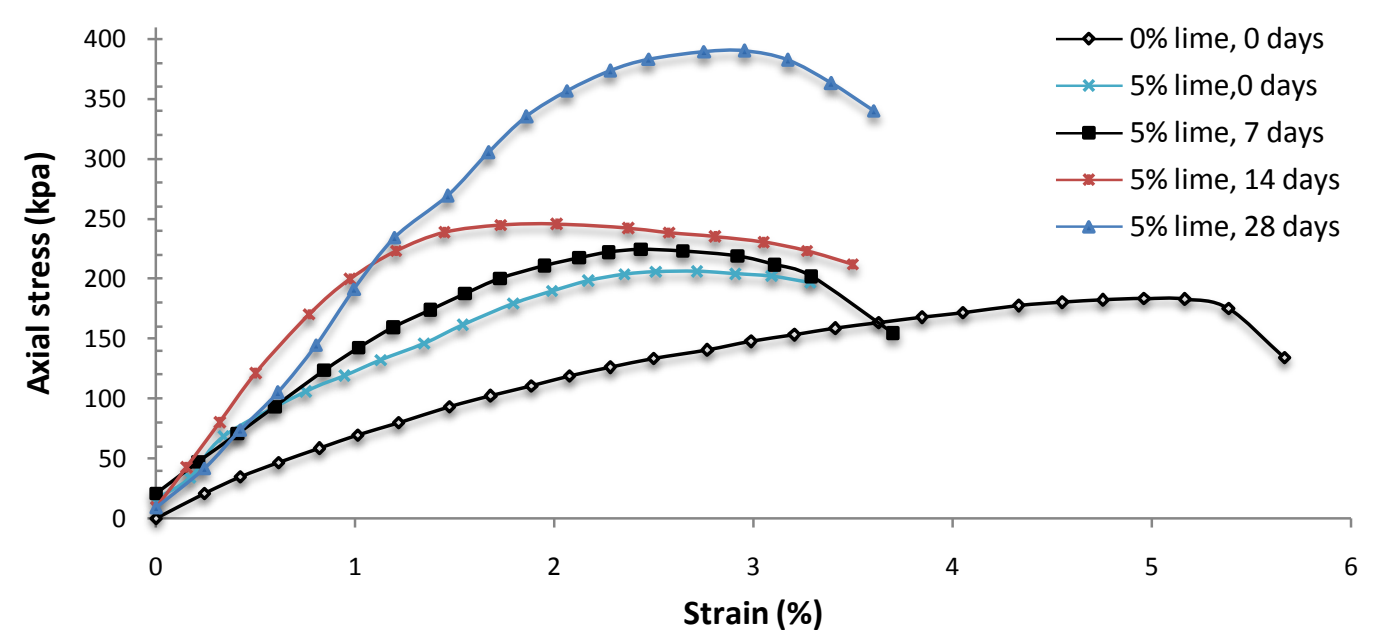

Fig. 4: Unconfined compression test curves

Figure 5 presents the relationship between the UCS and the curing time. As can be seen from Fig. 5, the limetreated soil exhibited a trend of increasing UCS with increasing curing time. For example, the UCS increased about twice of the original strength after 28 days curing. The summary of the UCS values is given in Table 2. 


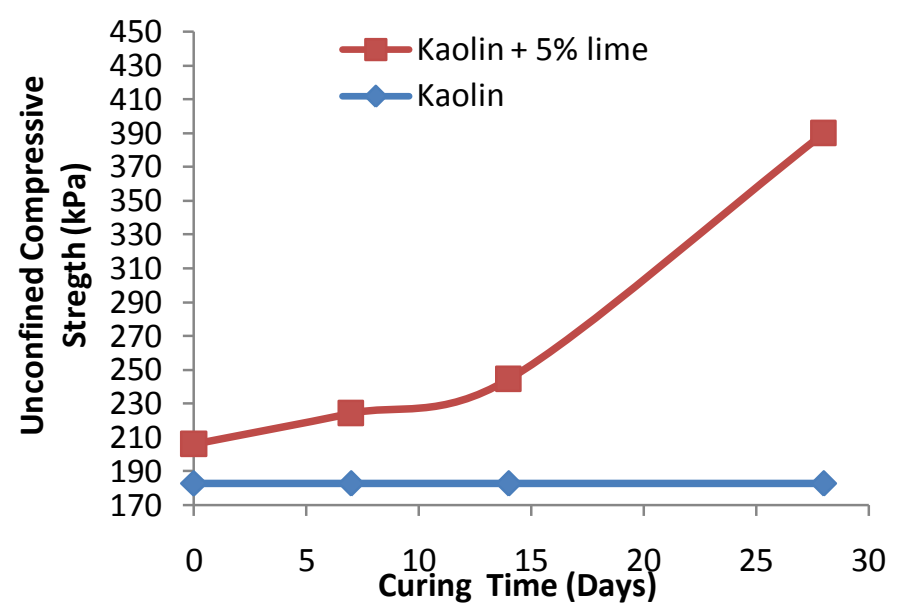

Fig.5: Influence of curing time on UCS of treated kaolin

Table 2: Summary of the unconfined compressive strengths

\begin{tabular}{lll} 
Description & Curing period (days) & UCS $(\mathrm{kPa})$ \\
\hline Kaolin & 0 & 183 \\
\hline \multirow{3}{*}{ Kaolin $+5 \%$ lime } & 0 & 206.2 \\
& 7 & 224.39 \\
& 14 & 244.67 \\
\hline
\end{tabular}

Fig. 6 presents the results of the UCS tests in terms of water content. The lime stabilised specimens at curing periods of 14 and 28 days achieved maximum strengths at optimum moisture content $(\mathrm{OMC}=33.3 \%)$ whereas for the wet side $(\mathrm{WMC}=37.5 \%)$ and the dry side $(\mathrm{DMC}=29.9 \%)$ of the OMC the UCS decreased for the same periods, even though they were still higher than the UCS of the untreated clay. The stabilised clay cured for 14 days experienced an increase from $189 \mathrm{kPa}$ to $205.2 \mathrm{kPaonWMC}$, while at 28 days of curing the increase was from $252.25 \mathrm{kPa}$ to $344.6 \mathrm{kPaonDMC}$. In other words, higher or lower than OMC water content decreases the UCS values compared to UCS at OMC. Similarly, [12] stated that the strength remains low with high water contents. The UCS decreases with the increasing water content because high water content prevents lime-clay contact; therefore, the bonding material created by the reaction between lime and clay particles is limited. This is on contrary to the priciples of the reaction required in lime stabilisation, where the chemical reaction needs more water to produce the pozzolanic materials.

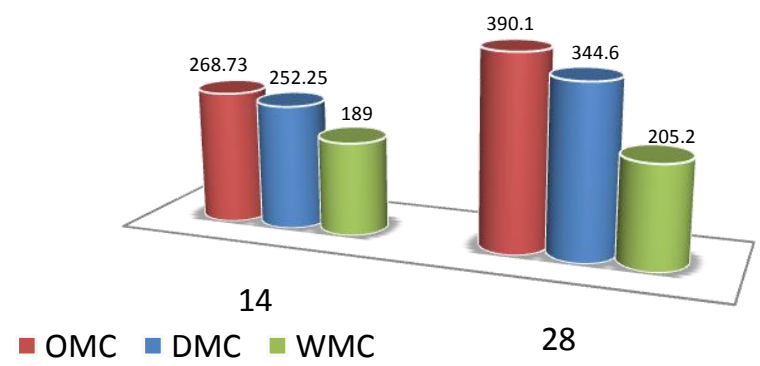

Fig. 6: Influence of water content on UCS of treated kaolin clay

\section{Microstructure Analysis}

SEM analysis was carried out on the same samples tested in unconfined compression tests. Lime treatment changed significantly the soil fabric depending on curing time and water content.

Fig. 7 shows the SEM-micrograph of untreated kaolin clay. As can be seen from the figure, hexagonal particles were observed and the clay displayed flaky texture which almost disappeared after 5\% addition of hydrated lime. 
The images of lime treated kaolin clay cured for 7, 14 and 28 days and compacted at moisture content of $33.3 \%$ (OMC) are shown in figures 8,9 and 10 respectively. As observed from the Figures, the clay particles transformed from a flaky form into a flocculating structure (Fig.8). With increasing curing period, there were morphology changes at the edges of clay particles and sufficient cementing compounds due to pozzolanic reaction coated and joined the soil particles together making the voids in the soil less distinct (Fig. 10). Similar findings were reported by [13] who found that new compounds in the form of white lumps were observed for longer curing time as a result of adding 5\% lime. It is expected that the new reaction products are fully formed after 28 days of curing.

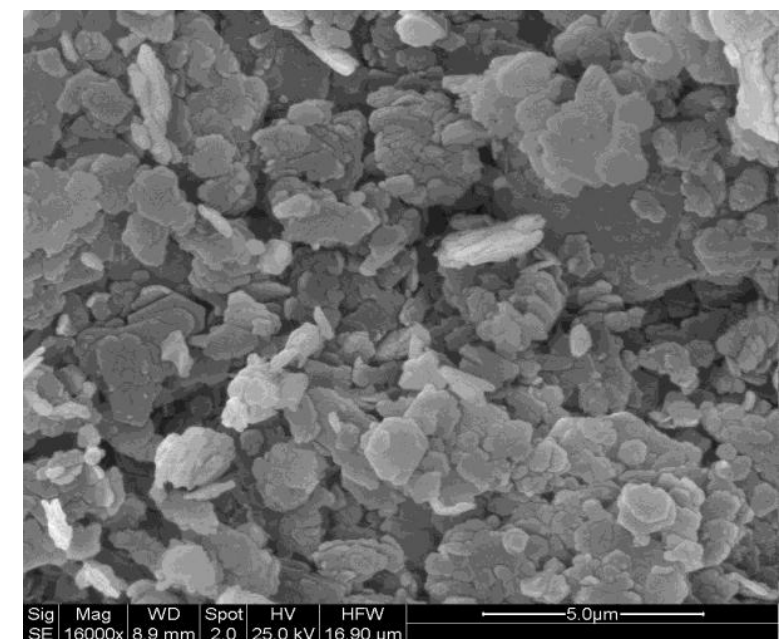

Fig. 7: SEM image of untreated kaolin clay $(O M C=29.9 \%)$

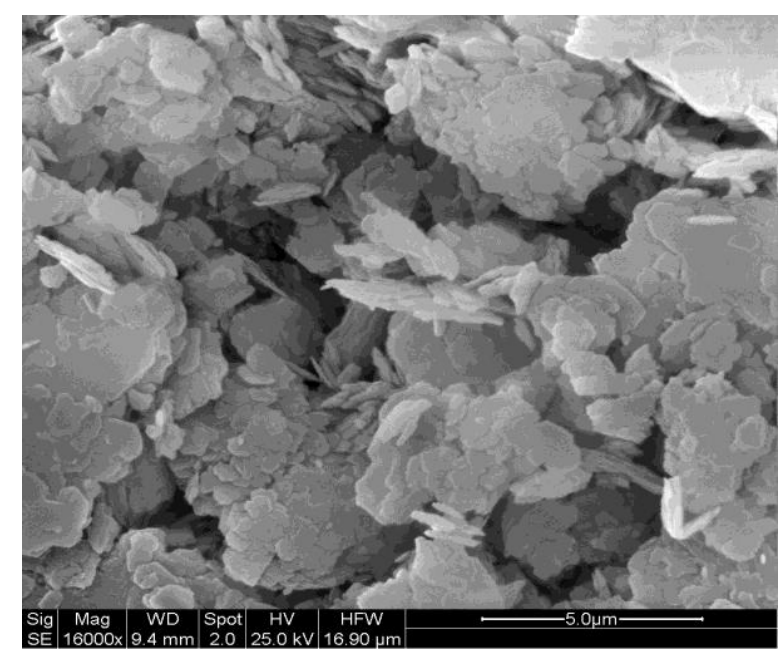

Fig. 9: SEM image of 5\% lime treated kaolin clay $(O M C=33.3 \%, 14$ days $)$

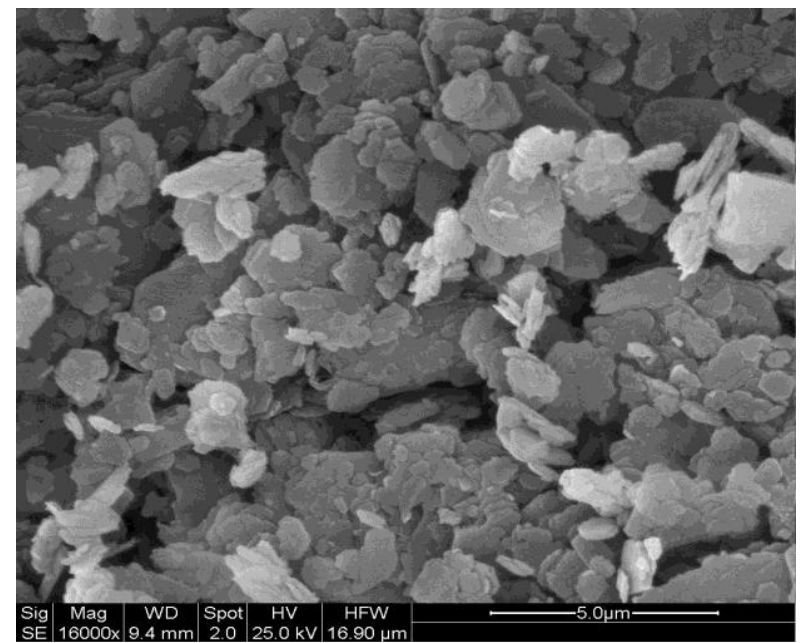

Fig. 8: SEM image of 5\% lime treated kaolin clay $(O M C=33.3 \%, 7$ days $)$

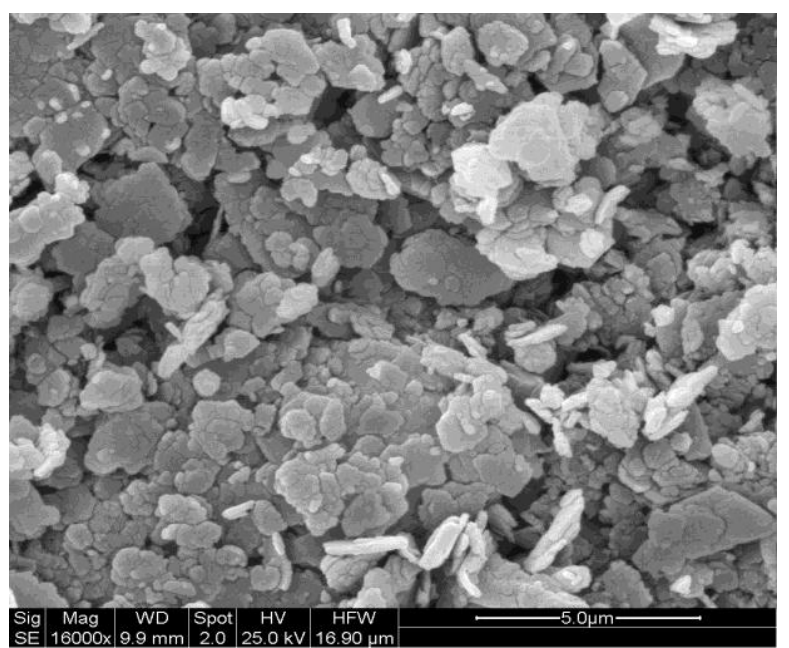

Fig. 10: SEM image of $5 \%$ lime treated kaolin clay $(O M C=33.3 \%, 28$ days $)$

In terms of water content, at the same compactive effort the clay particles became more oriented with increasing water content (Fig. 11). On wet side of OMC (37.5\%), increasing water content led to a more homogeneous microstructure (Fig. 12). More parallel particles and less voids are observed in Fig. 13 after 14 curing days compared to the lime treated soil of OMC at the same period. It is clearly noticed that the SEM image of the treated sample compacted at WMC and cured for 28 days has more voids than that compacted at OMC and cured for the same time (Fig.14).

Therefore, the reason for decreasing the unconfined compressive strength with increasing water content is related to these voids which are not filled with cementing products. The bonding of clay particles due to the pozzolanic reaction was limited by increasing water content. The microstructural analysis was in agreement with the results of strength tests. 


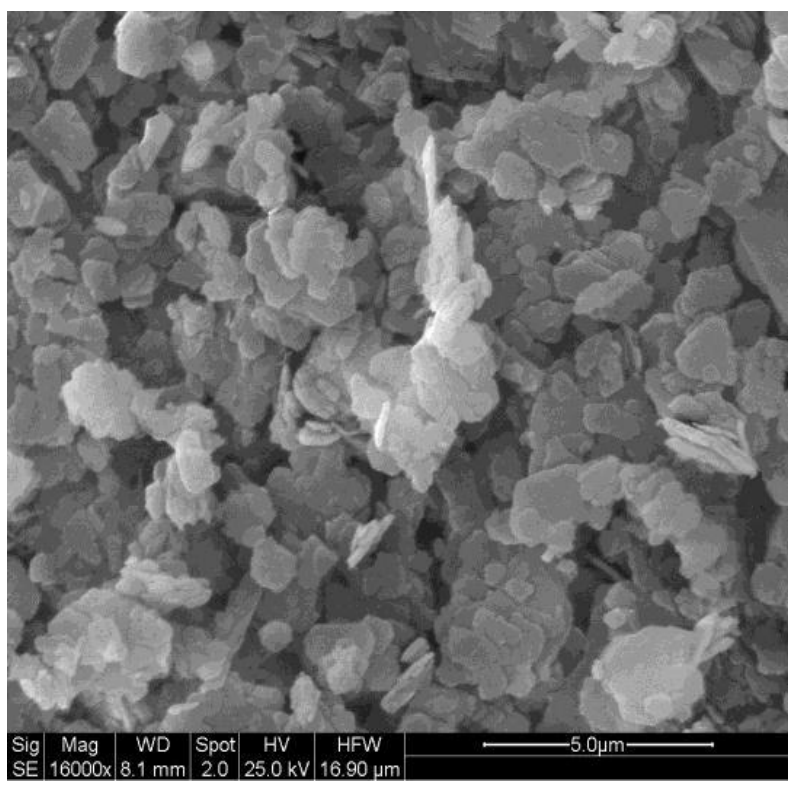

Fig. 11: SEM image of untreated kaolin clay $(W M C=33.3 \%)$

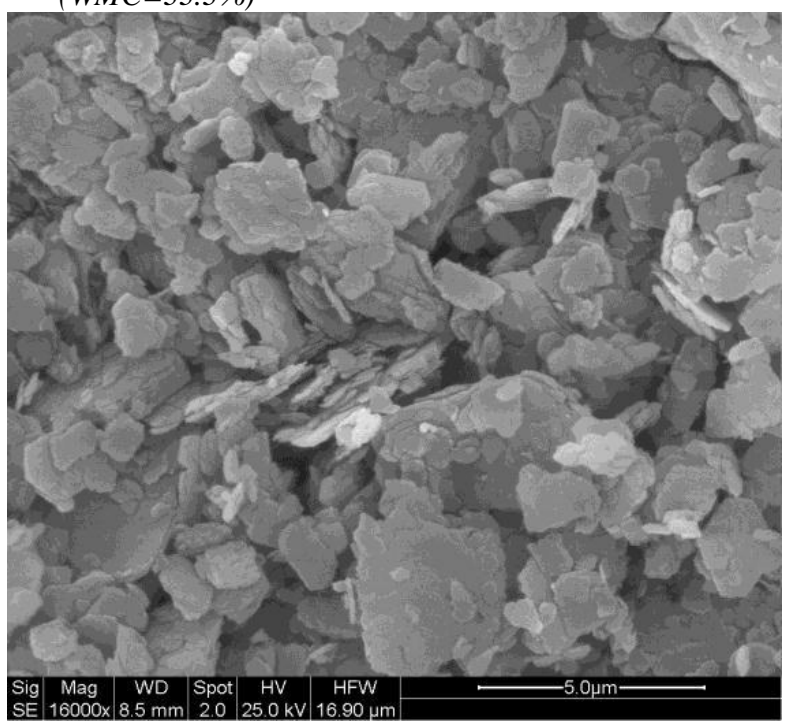

Fig. 13: SEM image of 5\% lime treated kaolin clay $(W M C=37.5 \%, 14$ days $)$

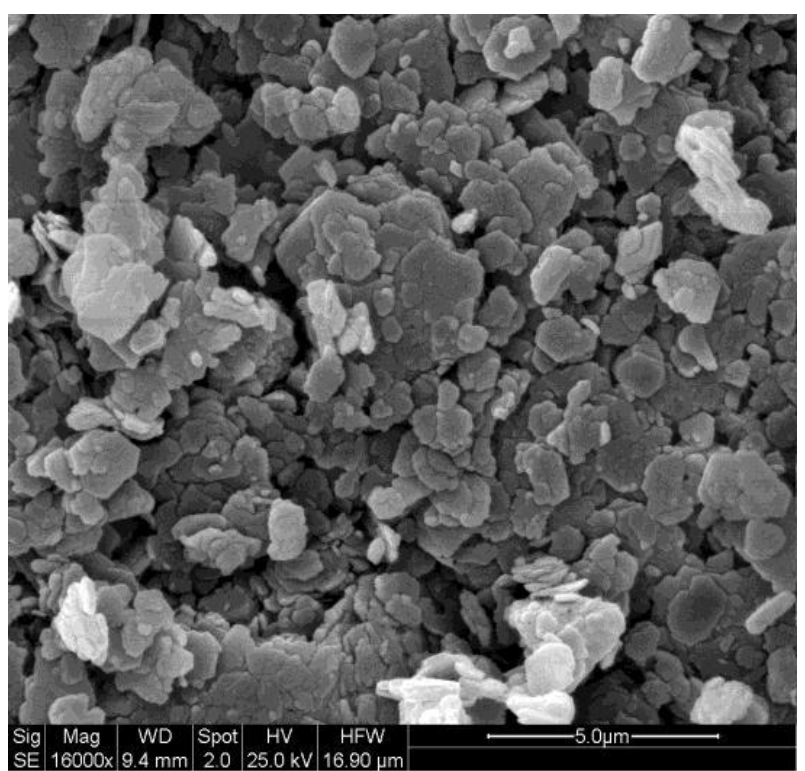

Fig. 12: SEM image of 5\% lime treated kaolin clay $(W M C=37.5 \%, 7$ days $)$

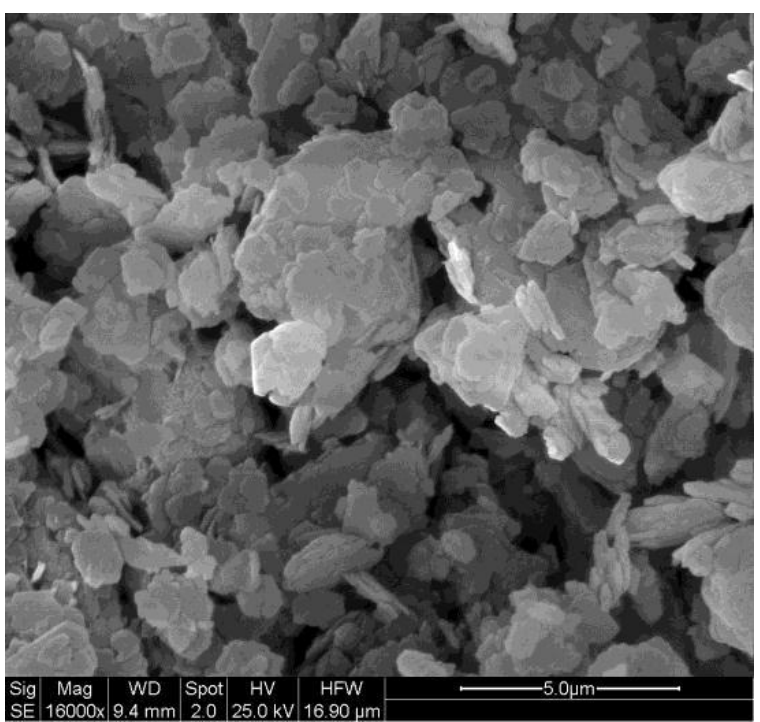

Fig. 14: SEM image of 5\% lime treated kaolin clay (WMC $=37.5 \%, 28$ days)

\section{Conclusion}

Based on the investigations carried out in this study, the following conclusions can be drawn:

- The addition of lime to the tested soil is found to increase the plastic and the liquid limits and decrease plasticity index. The plastic and liquid limits increased by $23.6 \%$ and $20.6 \%$ respectively, and the plasticity index decreased by $3 \%$.

- Lime treatment was able to increase the optimum moisture content from $29.9 \%$ to $33.3 \%$. In addition, the maximum dry density reduced by $40 \mathrm{~kg} / \mathrm{m}^{3}$ with lime addition. Therefore, lime content of $5 \%$ improved the compaction properties of the clay.

- The unconfined compressive strength of lime treated samples increased with increasing the curing period particularly after 28 days curing while it decreased with increasing water content. The added lime led to increase of around twice of the strength of the untreated clay. Contrary to curing time, water content, lower or higher than the OMC, decreased the strength of clay. These strength measurements correlate well with the laboratory data obtained by other researchers. 
- The behaviour and the fabric of treated soils shown by the SEM-micrographs indicated the formation of cementitous materials. These products resulted from the pozzolanic reactions contributed to the increase of the strength of stabilized clay. On the OMC, the microstructure of lime treated clay characterized by an assembly of clay materials whereas on the wet side of $\mathrm{OMC}$, increasing water content led to a homogeneous microstructure.

- From the results obtained in this study, it can be concluded that the hydrated lime effectively improve the strength, plasticity and compaction properties of kaolin clay.

\section{References}

[1] K. A. Gutschick(1967) Lime Stabilizes Poor Soils, the Aberdeen Group (Available at: http://www.concreteconstruction.net/concrete-articles/lime-stabilizes-poor-soils.aspx).

[2] T.Brandon, J.Brown, W.Daniels, T.DeFazio,G.Filz,J.Musselman, C. Forshaand,J. Mitchell (2009) 'Rapid Stabilisation/ Polymerization of Wet Clay soils; Literature Review', Air Force Research Laboratory, Blacksburg.

[3] D. N. Little (1999) Evaluation of Structural Properties of Lime stabilised soils and aggregates. The national lime association, Vol. 1 .

[4] J.L. Eadesand R.E. Grim(1966) A Quick Test to Determine Lime Requirements of Lime Stabilisation, Highway Research Record 139, pp. 61-72.

[5] J.L. Eadesand R.E. Grim(1960) The Reaction of Hydrated Lime with Pure Clay Minerals in Soil Stabilization, Highway Research Board 262, pp. 51-63.

[6] British Standard 1377, "Methods of test for soils for civil engineering purposes," British Standard Institution, London, 1990.

[7] A. Muzahimand L. Abdelmadjid(2008) Effect of Hydrated Lime on the Engineering Behaviour and the Microstructure of Highly Expansive Clay. In: The 12th International Conference of International Association for Computer Methods and Advances in Geomechanics, India, 1-6 October 2oo8.

[8] B. R. Phanikumar(2009) Effect of lime and fly ash on swell, consolidation and shear strength characteristics of expansive clays: a comparative study, Journal of Geomechanics and Geoengineering, 4(2), 175-181.

[9] F. G. Bell(1989) Lime Stabilization of Clay Soils, Bulletin of Engineering Geology and the Environment, 39(1), 67-74.

[10] T.S.Umesha, S.V. Dineshand P.V. Sivapullaiah(2009) Control of dispersivity of soil using lime and cement.International journal of geology.3(1), 8-15.

[11] D. T.Davidson, G. Nogueraand J. B. Sheeler (1960) Powder versus Slurry Application of Lime for Soil Stabilization. In: Papers on Soil 1959 Meetings, American Society for Testing Material, pp. 244-253.

[12] F. G. Bell (1993) Engineering Treatment of Soils, E \& FN Spon, London.

[13] K. A. Kassim(2009) The Nanostructure Study on the Mechanism of Lime Stabilised Soil, Research Vot No: 78011, Department of Geotechnics and Transportation, UniversitiTeknologi Malaysia. 